\title{
Effects of Streptozotocin, Bisphenol A and Diethylstilbestrol on Production of Reactive Oxygen Species and Lipid Peroxidation in the Boar Sperm
}

\author{
A-Sung Lee ${ }^{1}$, Sang-Hee Lee ${ }^{2}$, Seunghyung Lee ${ }^{1, \uparrow}$ and Boo-Keun Yang ${ }^{1, \uparrow}$ \\ ${ }^{1}$ College of Animal Life Sciences, ${ }^{2}$ Institute of Animal Resources, Kangwon National University, \\ Chuncheon 24341, Korea
}

\begin{abstract}
Streptozotocin (STZ), bisphenol A (BPA), and diethylstilbestrol (DES) are known as endocrine disruptors, occurs oxidative stress in animal cells. Generally, oxidative stress induces reactive oxygen species (ROS) and lipid peroxidation of sperm and lead to decreased viability and fertility in pigs. Therefore, we investigated the influence of STZ, BPA and DES on ROS production and lipid peroxidation on boar sperm. Collected sperm were incubated with semen extender containing $10 \mu \mathrm{M} \mathrm{STZ}, 10 \mu \mathrm{M}$ BPA and $20 \mu \mathrm{M}$ DES for 3, 6 and 9 hours. Intracellular ROS and lipid peroxidation of sperm were analyzed by 2', 7'-dichlorofluorescein diacetate and malondialdehyde methods. The results show that, intracellular ROS was not significantly different among the all treatments, but lipid peroxidation was significantly increased in STZ group at 3 hour after incubation with boar sperm $(P<0.05)$. These results suggest that STZ stimulates lipid peroxidation more than ROS production and may exert a negative effect on sperm fertility.
\end{abstract}

Key Words: Streptozotocin, Bisphenol A, Diethylstilbestrol, Reactive oxygen species, Lipid eroxidation, Sperm

Reactive oxygen species (ROS)는 산소를 포함하는 반응 성 화학 종으로 호흡과 광합성 같은 호기성 대사의 자연 부산물로 세포 내 적정수준의 ROS는 신호 전달 및 항상 성에 있어서 중요한 역할을 하지만, 과도한 수준의 ROS 가 발생할 경우 세포에 악영향을 미치게 된다(Squier, 2001; Singh et al., 2016). 이러한 ROS는 정액의 품질을 저하시키 는 요소 중 하나이며, 다른 세포에 비하여 정자의 세포막 에는 다량의 polyunsaturated fatty acids (PUFAs)가 함유되 어 있고, 이러한 PUFAs가 지니고 있는 다수의 이중결합 이 ROS에 민감하게 작용하기 때문이다(Wang et al., 1997; Kumaresan et al., 2009; Sapanidou et al., 2015). 또한 일반 체세포의 세포질 내에는 항산화효소(superoxide dismutase, glutathione peroxidase 및 catalase)가 다량으로 존재하나 정 자형성과정 중 다량의 세포질이 정자로부터 손실되기 때 문에 정자에는 ROS로부터 세포를 보호하는 항산화효소가 일반 체세포에 비하여 부족되어 결국 산화스트레스에 민 감하게 작용하게 된다(Kumaresan et al., 2009; Sapanidou et al., 2015). 결국 과도한 ROS는 정자의 구조와 이상적 기능 을 초래하여 세포막의 과산화 및 핵 내 DNA의 손상을 일 으켜 정자의 수정 능력을 저하시킨다(Guthrie and Welch, 2012; Kim et al., 2015; Tvrdá et al., 2015).

Streptozotocin (STZ)은 토양 미생물인 Streptomyces achromogenes에서 발견된 자연 발생 화합물로 세포 내 DNA alkylation 및 free radical을 생산하여 DNA를 손상시켜 세

* Received: April 25, 2017 / Revised: June 29, 2017 / Accepted: June 29, 2017

${ }^{\dagger}$ Corresponding author: Boo-Keun Yang. College of Animal Life Sciences, Kangwon National University, Chuncheon 24341, Korea.

Tel: +82-33-250-8623, Fax: +82-33-259-5572, e-mail: bkyang@kangwon.ac.kr

${ }^{\dagger}$ Corresponding author: Seunghyung Lee. College of Animal Life Sciences, Kangwon National University, Chuncheon 24341, Korea.

Tel: +82-33-250-8637, Fax:+82-33-259-5574, e-mail: s.lee@kangwon.ac.kr

(C) The Korean Society for Biomedical Laboratory Sciences. All rights reserved.

(c) This is an Open Access article distributed under the terms of the Creative Commons Attribution Non-Commercial License (http://creativecommons.org/licenses/by-nc/3.0/) which permits unrestricted non-commercial use, distribution, and reproduction in any medium, provided the original work is properly cited. 
포 사멸을 유도하며, 췌장 $\beta$-세포에 특이적으로 독성을 나타내는 것으로 보고되었다(King, 2012; Szkudelski, 2012). 또한 INS-1 세포에서 STZ의 처리는 세포 내 ROS를 다량 발생시키고 지질 과산화를 유발(Zheng et al., 2015) 시킨다 고 알려져 있으나 STZ에 의한 ROS의 작용기전은 아직까 지 명확하게 밝혀지지 않고 있으며, 포유동물 생식세포에 서 STZ가 ROS 변화와 이에 따라 발생하는 질병, 노화 및 난임과 같은 연구는 아직까지 충분하게 진행되지 않은 실 정이다. 따라서 본 연구는 돼지 정자에서 STZ가 ROS 생 산 및 지질 과산화 반응에 미치는 영향을 실시하였으며, 내분비교란물질과의 연관성도 알아보기 위하여 대표적인 물질 bisphenol A (BPA)와 diethylstilbestrol (DES)을 처리하 여 ROS 생산 및 지질 과산화 반응을 검토하였다.

본 실험에 사용된 시약 streptozotocin (STZ) 및 diethylstilbestrol (DES)은 Cayman (Ann Arbor, Michigan, USA)에서 구입하였으며, bisphenol A (BPA)은 Sigma-Aldrich (ST. Louis, Missouri, USA)에서 구입하였다. 또한 모든 동물실험은 강 원대학교 동물실험윤리위원회의 승인(KIACUC-09-0139) 을 얻어 수행하였다. 정액은 강원도 원주 영서 돼지 인공 수정센터의 3원교잡종(Duroc $\times$ Yorkshire $\times$ Landrace) 돼지에 서 음경수압법을 이용하여 채취되었으며, 정자의 운동성 이 $85 \%$ 이상인 정액을 Modena 희석액으로 $1 \times 10^{7}$ 정자/ $\mathrm{mL}$ 로 희석하여, $17^{\circ} \mathrm{C}$ 에 보관하며 실험에 사용하였다(Song et al., 2003). 실험에 사용된 정액은 BTS로 2회 세척 후 $2 \times 10^{6}$ 정자 $/ \mathrm{mL}$ 의 농도로 희석하여 $10 \mu \mathrm{M} \mathrm{STZ}, 10 \mu \mathrm{M}$ $\mathrm{BPA}$ 및 $20 \mu \mathrm{M} \mathrm{DES}$ 를 희석된 정액에 첨가하여 3,6 및 9시간 동안 $37^{\circ} \mathrm{C}, 5 \% \mathrm{CO}_{2}$ 환경에서 배양하였다. 배양이 완료된 정자는 $\mathrm{ROS}$ 생산 및 지질 과산화 반응을 측정하 는데 이용되었다.

정자 내 reactive oxygen species (ROS)는 2',7'-dichlorofluorescein diacetate (DCF-DA) assay로 측정하였다(Sung et al., 2016). DCF-DA가 산화되면서 형광을 띄는 2',7'-dichllorofluorescein (DCF)로 바뀌는 원리를 이용하여 생산된 ROS 는 $\mathrm{DCF}$ 표준곡선에 의해 정량화 하였다. $1 \times 10^{7}$ 정자 $/ \mathrm{mL}$ 농도의 $1 \mathrm{~mL}$ 정액 샘플을 $3,000 \mathrm{rpm}$ 의 조건으로 5 분 동안 원심분리한 후, 상층액 $200 \mu \mathrm{L}$ 을 $20 \mathrm{mM} \mathrm{DCF-DA} 20 \mu \mathrm{L}$ 와 혼합한 뒤 $37^{\circ} \mathrm{C}$ 배양기에서 30 분간 배양하였다. 이 후 배양된 샘플은 UV/VIS Fluorescence spectrophotometry (Excitation, $485 \mathrm{~nm}$, Emission $535 \mathrm{~nm}$ )를 사용하여 정자의 $\mathrm{ROS}$ 생산량을 측정하였다.

정자의 지질 과산화 반응은 thiobarbituric acid (TBA) 에 의해 생산된 malonaldehyde (MDA)와 반응하여 생성된 thiobarbituric acid-reactive substances (TBARS)의 생산량을 분광광도계를 이용하여 측정하는 방법으로 실시하였다. $1 \times 10^{7}$ 정자 $/ \mathrm{mL}$ 농도의 $1 \mathrm{~mL}$ 정액 샘플과 $500 \mu \mathrm{L} 40 \%$ trichloroacetic acid (TCA)를 혼합한 후, $0^{\circ} \mathrm{C}$ 에서 10 분간 정 치시켰다. 혼합된 정액 샘플을 $3,000 \mathrm{rpm}$ 조건에서 10 분 간 원심분리 후, 상층액을 사용하여 실험에 이용하였다. $1 \mathrm{~mL}$ 상층액과 $500 \mu \mathrm{L}$ 의 $2 \% \mathrm{TBA}(\mathrm{w} / \mathrm{v}, 0.2 \mathrm{~N} \mathrm{naOH})$ 를 혼 합하고, $100^{\circ} \mathrm{C}$ 에서 10 분간 가열하였다. 샘플은 실온에서 온도를 $4{ }^{\circ} \mathrm{C}$ 까지 하강시킨 후, 분광광도계의 $532 \mathrm{~nm}$ 파장 으로 지질 과산화 값을 측정하였다.

본 실험의 결과는 statistical analysis system software version 9.2 (SAS Institute Inc. USA)를 이용하여 Duncan 다 중검정 방법으로 유의성을 검정하였다.

배양 시간에 따라 $\mathrm{STZ}, \mathrm{BPA}$ 와 DES가 정자의 $\mathrm{ROS}$ 생 산에 대한 결과를 Fig. 1에 나타내었다. 측정된 ROS의 값 을 대조구로 일반화하여 상대적인 수치를 나타내었으며, 모든 $\mathrm{STZ}, \mathrm{BPA}$ 및 $\mathrm{DES}$ 처리구에서 배양 시간에 상관없 이 대조구와 비교하여 유의적인 차이가 나타나지 않았다. 최근 연구에 따르면, STZ는 세포 내 DNA alkylation 및 free radical을 생산하여 DNA 손상을 시켜 세포 사멸을 유 도하는 것으로 알려져 있다(King, 2012). 그러나, 본 연구 에서는 돼지 정자가 활성산소의 생산에는 영향을 미치지 않는 것으로 보아 세포의 종류에 따라서 활성산소의 생산 빈도가 다르게 영향을 미친 것으로 사료된다. 또한 췌장 $\beta$-세포에는 STZ가 침투하도록 세포막 표면에 포도당 수 송체인 glucose transporter (GLUT2)이 존재하며 이러한 경 로를 통하여 세포 내 독성을 유발하여 세포 사멸을 초래 하는 것으로 알려져 있다(Chen et al., 2001). 본 연구를 통 해 돼지 정자에서는 STZ가 ROS의 생산에는 영향을 미치 지 않는 것을 확인하였으며, 지질 과산화에는 영향을 미 친 것으로 판단할 때 다른 경로를 통하여 세포의 사멸 및 독성에 관여하여 정자세포의 성질에 변화를 초래된 것으 로 생각된다. 실제로 마우스 실험에서 고농도의 glucose가 ROS 생산을 증가(Jiang et al., 2010; Oliveira et al., 2015)시 킨다고 보고하였으며, STZ가 세포 내 ROS에 직접적으로 영향을 미치는 것이 아니라, glucose 농도의 증가로 인한 ROS 발생이 세포의 손상을 유도하는 것으로 판단된다. 따라서, STZ가 정자의 특성에 미치는 영향에 관한 분자 적 접근 방식의 연구가 지속적으로 진행되어야 할 것이다. 일반적으로 $\mathrm{BPA}$ 와 $\mathrm{DES}$ 는 $\mathrm{STZ}$ 와 같은 내분비 교란물질 로써 세포 내 ROS를 증가시킨다고 알려져 있다(Frye et al., 2012; Minamiyama et al., 2010). 본 연구에서는 내분비 
A

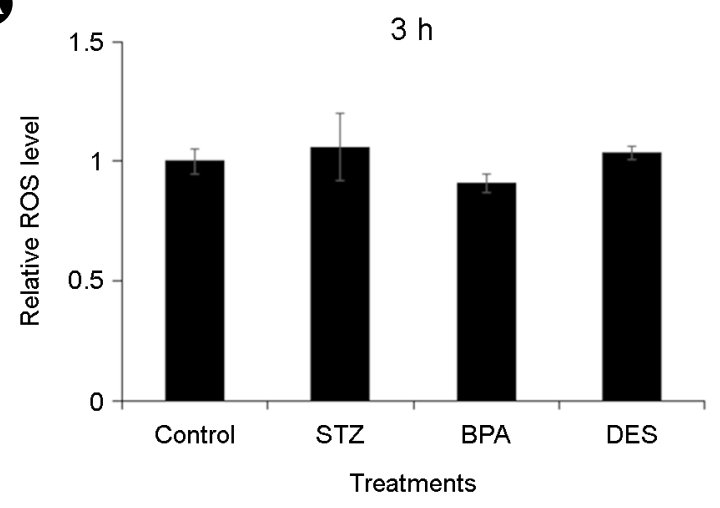

B

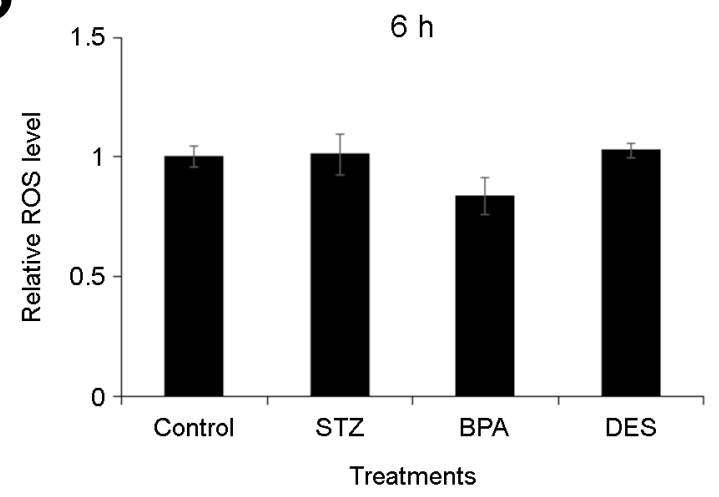

C

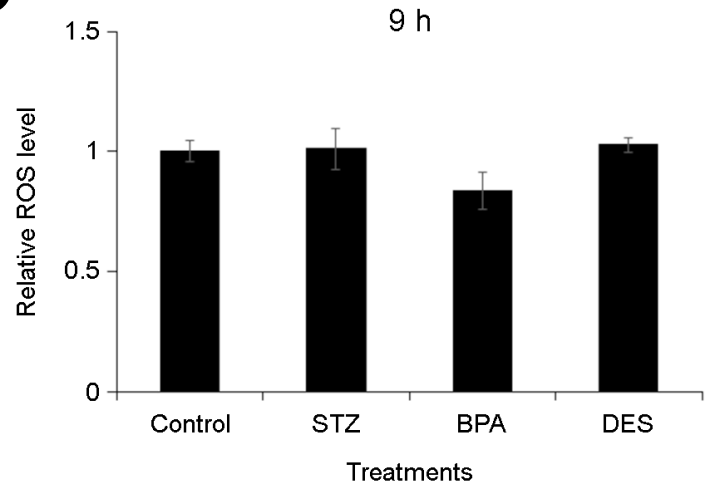

Fig. 1. Effect of streptozotocin (STZ), bisphenol A (BPA) and di-ethyl-stilbestrol (DES) on reactive oxygen species (ROS) production in boar sperm during liquid storage, $10 \mu \mathrm{M} \mathrm{STZ,} 10 \mu \mathrm{M}$ $\mathrm{BPA}$, and $20 \mu \mathrm{M}$ DES treated-boar sperm were analyzed ROS at $3 \mathrm{~h}(\mathrm{~A}), 6 \mathrm{~h}$ (B) and $9 \mathrm{~h}(\mathrm{C})$ by DCFDA method.

교란물질로 알려진 $\mathrm{BPA}$ 와 $\mathrm{DES}$ 가 돼지 정자의 미치는 영 향을 알아보기 위해 STZ와 함께 비교하여 실험을 진행하 였으며, 이러한 결과 BPA 및 DES 역시 ROS 생산과는 연관이 없다는 것을 실험을 통해 확인하였다. 실제로 몇

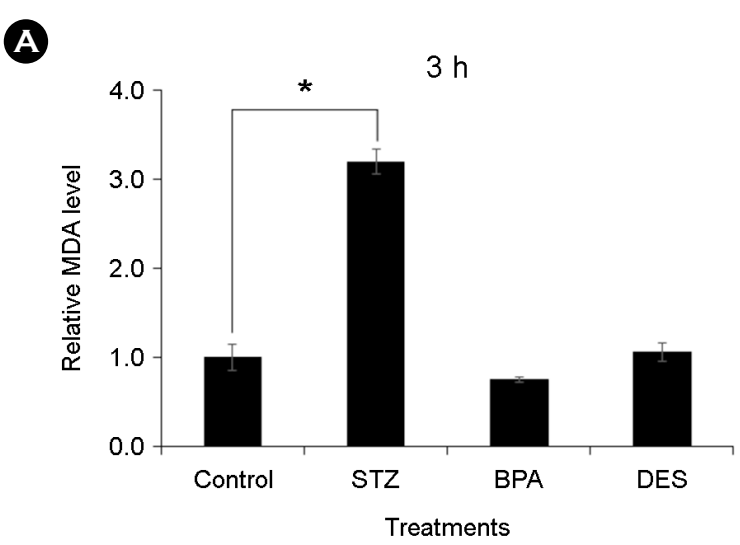

B
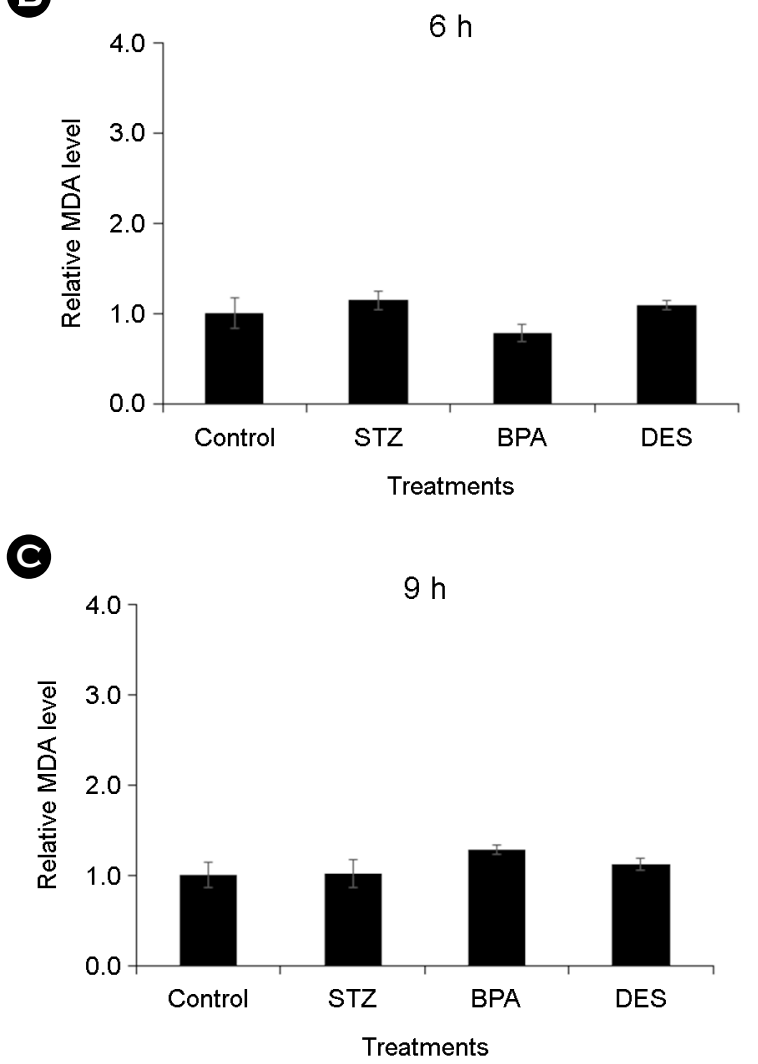

Fig. 2. Effect of streptozotocin (STZ), bisphenol A (BPA) and di-ethyl-stilbestrol (DES) on lipid peroxidation production in boar sperm during liquid storage, $10 \mu \mathrm{M} \mathrm{STZ,} 10 \mu \mathrm{M}$ BPA, and $20 \mu \mathrm{M}$ DES treated-boar sperm were analyzed lipid peroxidation at $3 \mathrm{~h}(\mathrm{~A})$, $6 \mathrm{~h}$ (B) and $9 \mathrm{~h}(\mathrm{C})$ by malonaldehyde (MDA) method, ${ }^{*} P<0.05$.

몇 세포에서는 $\mathrm{BPA}$ 와 DES가 ROS 생산을 유도한다는 연 구가 보고되고 있으나(Srivastava et al., 2015; Tiwari et al., 2012), 본 연구에서는 정자의 ROS 발생을 촉진시키지 않 는 것으로 나타났다. 
$\mathrm{STZ}, \mathrm{BPA}$ 및 DES에 의한 정자의 지질 과산화를 Fig. 2 에서 나타내었다. 그 결과, STZ 처리 후 3시간에서 대조 구에 비하여 유의적으로 지질 과산화가 증가한 것으로 나 타났다(Fig. 2A). 그러나, BPA와 DES 처리구에서는 배양 시간과 무관하게 유의적인 차이가 나타나지 않았다. 일반 적으로, 세포는 인지질 및 단백질 분자들로 구성된 인지 질 이중층으로 구성된 세포막을 지니고 있다. 이러한 세 포의 항상성이 유지되지 않으면, 세포막이 손상되고 세포 의 사멸이 유도된다(Catalá, 2007). 특히, 돼지 정자의 세포 막에는 PUFAs가 풍부하며, PUFAs는 많은 이중결합을 지 니고 있어 활성산소와의 반응이 높아지기 때문에 세포의 손상이 쉽게 발생되고 bacteria에 의한 활성산소 역시 증 가되는 것으로 보고되고 있다(Fraczek et al., 2007; Wathes et al., 2007). 또한, 마우스에서 STZ는 신장, 간 및 심장 에서 지질 과산화 정도가 증가하는 것으로 보고되었다 (Hosseini et al., 2017; Roslan et al., 2017). 따라서, STZ가 돼 지 정자 내 ROS 생산을 직접적으로 유도하기 보다는 지 질 과산화를 촉진시켜 정자세포에 손상을 일으키는 것으 로 판단된다. $\mathrm{BPA}$ 는 방향족 화합물로 생물에 있어 다양 한 악영향을 주는 것으로 널리 알려져 있고, $\mathrm{BPA}$ 가 간 과 신장 및 뇌 등의 여러 기관에서 $\mathrm{ROS}$ 를 발생시켜 세 포의 손상을 일으키고, 항산화효소의 활성을 억제시켜 지 질 과산화를 증가시키는 것으로 보고되고 있다(Tiwari et al., 2012). 합성 에스트로겐인 DES는 RAW cell에서 쉽게 산화(Oda and Kaneko, 2002). 쥐 정자의 지질 과산화를 유 도(Minamiyama et al., 2010)한다고 알려져 있다. 하지만 본 연구에서 돼지 정자에 있어 배양 시간에 따라 $\mathrm{BPA}$ 및 $\mathrm{DES}$ 는 지질 과산화에 영향을 미치지 않았으며, 내분비교 란물질인 $\mathrm{BPA}$ 와 $\mathrm{DES}$ 는 정자의 지질 과산화 반응에 직접 적으로 관여하지 않는 것으로 판단되나, 정자세포의 생존 및 사멸에 관여하는 유전학적 연구가 지속적으로 실시되 어 내분비교란물질이 정자의 특성에 미치는 구체적인 원 인을 밝혀내야 할 것이다.

\section{ACKNOWLEDGEMENTS}

2016년도 강원대학교 대학회계 학술연구조성비로 연구 하였음(관리번호-520160128).

\section{CONFLICT OF INTEREST}

The authors have no conflicts of interest to disclose.

\section{REFERENCES}

Catala A. The ability of melatonin to counteract lipid peroxidation in biological membranes. Current Molecular Medicine. 2007. 7: 638-649.

Chen H, Carlson EC, Pellet L, Moritz JT, Epstein PN. Overexpression of metallothionein in pancreatic beta-cells reduces streptozotocin-induced DNA damage and diabetes. Diabetes. 2001. 50: 2040-2046.

Fraczek M, Szumala-Kakol A, Jedrzejczak P, Kamieniczna M, Kurpisz M. Bacteria trigger oxygen radical release and sperm lipid peroxidation in in vitro model of semen inflammation. Fertility and Sterility. 2007. 88: 1076-1085.

Frye CA, Bo E, Calamandrei G, Calzà L, Dessì-Fulgheri F, Fernández M, Fusani L, Kah O, Kajta M, Le Page Y, Patisaul HB, Venerosi A, Wojtowicz AK, Panzica GC. Endocrine disrupters: a review of some sources, effects, and mechanisms of actions on behaviour and neuroendocrine systems. Journal of Neuroendocrinology. 2012. 24: 144-159.

Guthrie HD, Welch GR. Effects of reactive oxygen species on sperm function. Theriogenology. 2012. 78: 1700-1708.

Hosseini A, Mollazadeh H, Amiri MS, Sadeghnia HR, Ghorbani A. Effects of a standardized extract of Rheum turkestanicum Janischew root on diabetic changes in the kidney, liver and heart of streptozotocin-induced diabetic rats. Biomedicine \& Pharmacotherapy. 2017. 86: 605-611.

Jiang T, Huang Z, Lin Y, Zhang Z, Fang D, Zhang DD. The protective role of Nrf2 in streptozotocin-induced diabetic nephropathy. Diabetes. 2010. 59: 850-860.

Khaki A, Fathiazad F, Nouri M, Khaki A, Maleki NA, Khamnei HJ, Ahmadi P. Beneficial effects of quercetin on sperm parameters in streptozotocin-induced diabetic male rats. Phytotherapy Research. 2010. 24: 1285-1291.

Kim Y-J, Lee S-H, Yang J-W, Lee Y-J, Choi S-B, Lee K-J, S Lee, C-K Park. Effect of nicotinic acid on frozen-thawed sperm characteristics in bulls. Annals of Animal Resource Sciences. 2015. 26: 75-84.

King AJ. The use of animal models in diabetes research. British Journal of Pharmacology. 2012. 166: 877-894.

Kumaresan A, Kadirvel G, Bujarbaruah KM, Bardoloi RK, Das A, Kumar S, Naskar S. Preservation of boar semen at 18 degrees $\mathrm{C}$ induces lipid peroxidation and apoptosis like changes in spermatozoa. Animal Reproduction Science. 2009. 110: 162 -171 . 
Minamiyama Y, Ichikawa H, Takemura S, Kusunoki H, Naito Y, Yoshikawa T. Generation of reactive oxygen species in sperms of rats as an earlier marker for evaluating the toxicity of endocrine-disrupting chemicals. Free Radical Research. 2010. 44: 1398-1406.

Oda T, Kaneko M. Formation of active oxygen species from diethylstilbestrol, a synthetic estrogen, and its metabolite in the presence of RAW 264.7 cells. Biological \& Pharmaceutical Bulletin. 2002. 25: 1311-1314.

Oliveira PF, Tomás GD, Dias TR, Martins AD, Rato L, Alves MG, Silva BM. White tea consumption restores sperm quality in prediabetic rats preventing testicular oxidative damage. Reproductive Biomedicine Online. 2015. 31: 544-556.

Roslan J, Giribabu N, Karim K, Salleh N. Quercetin ameliorates oxidative stress, inflammation and apoptosis in the heart of streptozotocin-nicotinamide-induced adult male diabetic rats. Biomedicine \& Pharmacotherapy. 2017. 86: 570-582.

Sapanidou V, Taitzoglou I, Tsakmakidis I, Kourtzelis I, Fletouris D, Theodoridis A, Zervos I, Tsantarliotou M. Antioxidant effect of crocin on bovine sperm quality and in vitro fertilization. Theriogenology. 2015. 84: 1273-1282.

Singh R, Parihar P, Singh S, Mishra RK, Singh VP, Prasad SM. Reactive oxygen species signaling and stomatal movement: Current updates and future perspectives. Redox Biology. 2016. 11: 213-218.

Song MS, Han KS, Hwang HS, Kim JT, Park CK, Kim CI, Cheong HT, Jang HY, Lee HK, Yang BK. Effect of taurine on sperm characteristics in fresh boar semen during in vitro storage. Annals of Animal Resource Sciences. 2003. 14: 10-19.

Squier TC. Oxidative stress and protein aggregation during biological aging. Experimental Gerontology. 2001. 36: 1539-1550.

Srivastava S, Gupta P, Chandolia A, Alam I. Bisphenol A: a threat to human health? Journal of Environmental Health. 2015. 77: 20-26.
Sung HJ, Jeong YJ, Kim J, Jung E, Jun JH. Soybean peptides induce apoptosis in HeLa cells by increasing oxidative stress. Biomedical Science Letters. 2016. 21: 77-83.

Szkudelski T. The mechanism of alloxan and streptozotocin action in B cells of the rat pancreas. Physiological Research. 2012. 50: 537-546.

Tiwari D, Kamble J, Chilgunde S, Patil P, Maru G, Kawle D, Bhartiya U, Joseph L, Vanage G. Clastogenic and mutagenic effects of bisphenol A: an endocrine disruptor. Mutation Research. 2012. 743: 83-90.

Tvrdá E, Kováčik A, Tušimová E, Massányi P, Lukáč N. Resveratrol offers protection to oxidative stress induced by ferrous ascorbate in bovine spermatozoa. Journal of Environmental Science and Health. Part A, Toxic/Hazardous Substances \& Environmental Engineering. 2015. 50: 1440-1451.

Wang Y, Sharma RK, Agarwal A. Effect of cryopreservation and sperm concentration on lipid peroxidation in human semen. Urology. 1997. 50: 409-413.

Wathes DC, Abayasekara DR, Aitken RJ. Polyunsaturated fatty acids in male and female reproduction. Biology of Reproduction. 2007. 77: 190-201.

Zheng S, Zhao M, Ren Y, Wu Y, Yang J. Sesamin suppresses STZ induced INS-1 cell apoptosis through inhibition of NF- $\mathrm{kB}$ activation and regulation of Bcl-2 family protein expression. European Journal of Pharmacology. 2015. 750: 52-58.

http://dx.doi.org/10.15616/BSL.2017.23.2.128

Cite this article as: Lee AS, Lee SH, Lee S, Yang BK. Effects of Streptozotocin, Bisphenol A and Diethylstilbestrol on Production of Reactive Oxygen Species and Lipid Peroxidation in the Boar Sperm. Biomedical Science Letters. 2017. 23: 128-132. 